\title{
Editorial
}

\section{Artificial Intelligence in Dentistry: Will it displace human touch?}

\author{
Vineeta Nikhil ${ }^{1}$,* \\ ${ }^{1}$ Dept. of Conservative Dentistry and Endodontics, Subharti Dental College \& Hospital, Meerut, Uttar Pradesh, India
}

\section{A R T I C L E I N F O}

Article history:

Received 24-12-2021

Accepted 27-12-2021

Available online 28-12-2021
This is an Open Access (OA) journal, and articles are distributed under the terms of the Creative Commons Attribution-NonCommercial-ShareAlike 4.0 License, which allows others to remix, tweak, and build upon the work non-commercially, as long as appropriate credit is given and the new creations are licensed under the identical terms.

For reprints contact: reprint@ipinnovative.com

\section{Jai Hind Friends,}

As the present year is passing, it is opening the doors for new year and a new beginning. The technological revolution is rapidly changing our lives, drastically affecting how we work, learn, and even live together. With the sophisticated use of big data, Artificial Intelligence (AI) is exploding and finding new applications in a growing variety of fields, including security, the environment, research, education and health.

The Council on Artificial Intelligence recommended definition of AI as "An Artificial Intelligence system is a machine-based system that can, for a given set of humandefined objectives, make predictions, recommendations, or decisions influencing real or virtual environments." AI systems are designed to operate with varying levels of autonomy. AI is not a narrow field, rather it is a vast field which occurs in three stages: Narrow, General and Super. AI includes machine learning (Supervised, unsupervised and reinforcement), deep learning, natural language processing, expert systems, image recognition, object detection and so on.

Computers have already become an essentiality in dental practice, and a computer integrated with intelligence can make dentistry further easy. Presently AI can be used in dentistry for various applications e.g. diagnosis of dental diseases, planning treatment in complex or complicated

\footnotetext{
* Corresponding author.

E-mail address: endobyvineeta@gmail.com (V. Nikhil).
}

cases, clinical decision-making and prediction of prognosis.

Referring to our speciality, AI in Endodontics is very much helpful in detecting vertical root fracture, locating apical foramen and determination of working length, prediction of periapical pathosis, assessment of root morphologies, retreatment procedures etc. ${ }^{1}$ The digital assistance system in the newer generation endomotor uses complex algorithms to controls the variable file movements at miliseconds, a speed that far exceeds a person's ability to react. AI assisted endomotor have the ability to guide the dentist for rinse and file change during root canal preparation thus decreasing the stress. In nutshell, development in endodontics incorporating AI goes beyond our imaginations.

The potential applications of AI in dentistry addressed by many researchers, ${ }^{2-5}$ however, it is giving rise to the burning questions e.g. Will the AI integrated Dentistry replace the dental professionals or could it negatively affect the health sector by limiting or degrading the skills of health workers? To the best of my understanding of AI and its integration with dentistry, there is only a theoretical possibility of such happening. The reasons are many, but the most important amongst them is empathy. Empathy cannot be replaced, as it is very difficult to mimic compassion by even technologically very smart machines. At the core of compassion, is the process of building trust by listening to the patient, paying attention to their needs, expressing the feeling of understanding and responding in a manner that the patient knows they were understood. Additionally as each 
patient and their life style is different. Setting up a diagnosis and treating a patient is not a linear process, it requires creativity and problem solving skills that algorithms and robots will never have. No robot or algorithm could interpret complex, multilayer challenges involving psyche. While they will provide the data, interpretation will always remain a human territory. That's why everyone of them require human attention.

There are also few ethical issues associated with AI like privacy, data security and responsibility. Who will be held responsible if an AI assisted dental decision causes harm to a patient? Will it be the company who had manufactured the machine or the machine holder?

As the preliminary results of the various AI systems developed for different applications in dentistry have produced hopeful results, a future for AI in the dental care system appears to be bright. ${ }^{6}$ Therefore, I view it as a supportive gift of technology to assist dentist professionals and make their work easy and less stressful. But this will definitely require prior training for which we have to prepare our institutions for the facilities required for training.

Wishing you all a very Happy New Year 2022

\section{References}

1. Aminoshariae A, Kulild J, Nagendrababu V. Artificial Intelligence in Endodontics: Current Applications and Future Directions. J Endod. 2021;47(9):1352-7. do1:10.1016/].joen.2021.06.003.
2. Lee JH, Kim DH, Jeong SN, Choi SH. Detection and diagnosis of dental caries using a deep learning-based convolutional neural network algorithm. J Dent. 2018;77:106-11. do1:10.1016/j.jdent.2018.07.015.

3. Xie X, Wang L, Wang A. Artificial neural network modeling for deciding if extractions are necessary prior to orthodontic treatment.

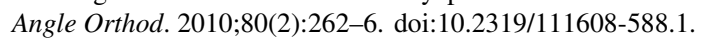

4. Lee JH, Kim DH, Jegon SN, Choi SH. Diagnosis and prediction of periodontally compromised teeth using a deep learning-based convolutional neural network algorithm. J Periodontal Implant Sci. 2018;48(2):114-23. doi:10.5051/jpis.2018.48.2.114.

5. Poedjiastoeti W, Suebnukarn S. Application of convolutional neural network in the diagnosis of jaw tumors. Healthc Inform Res. 2018;24(3):236-41. d01:10.4258/hir:201824.3236.

6. Nguyen TT, Larrivée N, Lee A, Bilaniuk O, Durand R. Use of Artificial Intelligence in Dentistry: Current Clinical Trends and Research Advances. J Can Dent Assoc. 2021;87:17.

\section{Author biography}

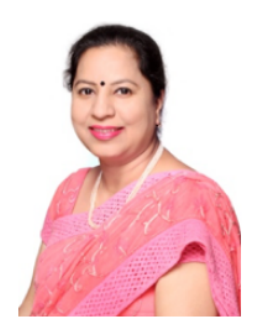

Vineeta Nikhil, Editor in Chief:- Indian Journal of Conservative and Endodontics Director PG Studies; Professor and Head Subharti Dental College \& Hospital, Meerut, Uttar Pradesh, India (D) https://orcid.org/00000003-3954-5676

Cite this article: Nikhil V. Artificial Intelligence in Dentistry: Will it displace human touch?. IP Indian J Conserv Endod 2021;6(4):189-190. 